\title{
FRAGMENTED OR COMPACT: THE CASE OF PERIURBAN MUNICIPALITIES IN THE NORTHWEST OF THE METROPOLITAN AREA OF BUENOS AIRES
}

\author{
A. P. Flores ${ }^{1 *}$, M. E. Gaudiano ${ }^{2}$ \\ ${ }^{1}$ Instituto del Conurbano, Universidad Nacional de General Sarmiento, Prov. de Buenos Aires Argentina - pflores@ungs.edu.ar \\ ${ }^{2}$ Centro de Investigación y Estudios de Matemática, CONICET Universidad Nacional de Córdoba, Prov. de Córdoba, Argentina \\ marcosgaudiano@gmail.com
}

KEY WORDS: urbanization, impervious areas, zoning, fractal dimension, land use

\begin{abstract}
:
The accelerated growth of cities since the middle of the last century occupies a prominent place in urban agendas. The development of planning strategies depends on the knowledge and understanding this phenomenon. Therefore, identifying the modification pattern in the spatial configuration is of paramount importance. In this sense, the high level of detail offered by remote sensing technologies makes it possible to estimate the distribution of human settlements and their relationship to other coverages. The information obtained allows to analyze spatial contiguity and general expansion but other indicators are needed to identify spatial singularities. This work aims to present a compaction indicator and fragmentation indicator, useful for identifying local configuration patterns and their temporal variation. The study area consists of the Moreno, Pilar, Gral Rodriguez, Luján and Mercedes municipalities of the metropolitan area of Buenos Aires (AMBA) for the period 1986-2019. The results indicate an increase in impervious surfaces higher than $300 \%$ in this period and the detection of new urban centres in those municipalities. In the future it is hoped to replicate the techniques presented throughout the AMBA in order to contribute to medium and long-term territorial planning.
\end{abstract}

\section{INTRODUCTION}

\subsection{Urban expansion}

Since the middle of the last century, the growth of cities has been of relevance in urban agendas, especially in Latin America metropolitan areas. This phenomenon brought together experts from academia and politics since the 1950s, who discussed how to measure, characterize and explain spatial processes. In this context, cartography is a key instrument for characterizing sizes, location, growth trends and other spatial variables (Favelukes, Novick, \& Zanzottera, 2016).

In recent decades, the evolution of computer resources for data management and the availability of satellite information have facilitated the study and monitoring of land uses. The continuous and systematic collection of data has made it possible to describe and quantify the evolution of human settlements with a high degree of precision (Masek, Lindsay, \& Goward, 2000; Schneider \& Woodcock, 2008; Taubenböck et al., 2012; Zhang \& Xu, 2018).

While obtaining land cover is in itself a task that includes precise methods, after obtaining them the analysis of land use change requires the calculation of comparison metrics. Metrics describe the pattern of change in urban configurations; help to improve the measurement of density of cities and to prevent the cost of infrastructure provision. The most commonly used metrics in the study of urban environment fragmentation come from the biological sciences and evaluate open or vacant spaces with respect to their neighbourhood (Angel, 2010).

However, few metrics allow the analysis of similar objects at different scales. The most explored is the fractal dimension (D) that indexes and hierarchically orders land occupation patterns (Shen, 2002; Encarnação, Gaudiano, Santos, Tenedório, \& Pacheco, 2012). D is able to identify areas with a high degree of irregularity and fragmentation, as well as those with greater agglutination and compaction.

Applying metrics at different scales and combining them with demographic and economic information would make it possible to understand the particularities of urban transformation and be able to predict its behaviour (Longley, P A, 1999; Swenson \& Franklin, 2000). This article presents descriptive statistics based on fragmentation metrics calculated in peripheral municipalities of Metropolitan Area of Buenos Aires (AMBA) in the period 1986-2019.

\subsection{Study Area}

The study area is the northwest of AMBA and includes the municipalities of Mercedes, Luján, Gral Rodriguez, Pilar and Moreno (Fig. 1). The activities developed in the area are related to agricultural and industrial production $(67.08 \%$ and $4.14 \%$, respectively) and to urban centres (26.23\%) (see Appendix Fig 7 for details). Data collected from the last National Census of Population indicate a sustained population growth from 610,581 people in 1991 , to 843,663 in 2001 to $1,018,180$ in 2010 (National Institute for Statistics and Census, n.d.). Most of the inhabitants are concentrated in the cities of Moreno (45.5\%) and Pilar (25\%).

\footnotetext{
Corresponding author
} 


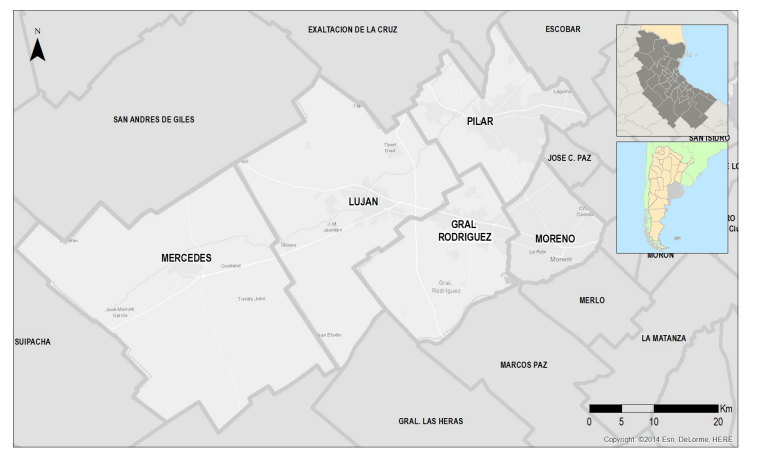

Figure 1. Map of the study area

\section{MATERIAL AND METHODS}

\subsection{Land-use change analysis}

Impervious surface is the main indicator of land-use change. It is estimated using supervised classification techniques applied on LANDSAT (USGS) satellite images. The years under consideration were 1986, 2001 and 2019; we selected one cloud-free image per year. The first two images were acquired from the Thematic Mapper sensor and the last from the Operational Land Imager (OLI) sensor. The Landsat imagery (reflectance at the top of the atmosphere, TOA) was obtained from the Google Earth Engine platform (Gorelick et al., 2017).

A normalized spectral difference vector (NDSV) was constructed prior to the classification to maximize differences in reflectance between land cover classes (Eq. 1) (Angiuli \& Trianni, 2014; Patel et al., 2015).

$$
\begin{aligned}
& \operatorname{NDSV}_{i j}=\left(b_{i}-b_{j}\right) /\left(b_{i}+b_{j}\right) \\
& \text { where } \quad b_{i}, b_{j}=\text { the band pairs for each image }
\end{aligned}
$$

The supervised classification of the NDSV images was then performed applying Support Vector Machine -SVM- algorithm (Burges, C. J. C., 1998) developed in ENVI.

The training areas were obtained using hyperspectral and Very High Resolution (VHR) data. The first were provided by EarthObserving One (EO-1) Hyperion Imaging Spectrometer. The most spectrally pure pixels (endmembers) were extracted using the Pixel Purity and N-Findr algorithms. After, we computed Linear Spectral Unmixing to determine the relative abundance of materials that are depicted on hyperspectral imagery. Finally, pixels with a purity percentage higher than $75 \%$ were chosen for each detected endmember (Flores, 2017).

The second type of data was provided by QuickBird satellite imagery extracted from Google Earth Pro ${ }^{\mathrm{TM}}$. We assumed that the areas with some kind of building or with street layouts observed in past images were still present. To confirm that these areas had the same type of land cover in 1986 and 2001, we obtained official information on land cover/use during this time period. Satellite-based training set were regrouped into five classes: 1) impervious surface (-household roof made of tiles, concrete blocks, corrugated zinc sheets, or with radiant barrier-, pavement and parking lot), 2) tree, 3) herbaceous vegetation, 4) water body and 5) bare soil (including unpaved road). To identify the pervious surface (classes 2-5); we examined the complete imagery catalogue and selected areas that remained unchanged in 1986, 2001 and 2019. As a result, $65 \%$ of the samples were selected for training and the remaining samples were used to validate the obtained classification.

To estimate the impervious surface temporal variation, images were reclassified according to the binary categories pervious (value $=0$ ) and impervious (value $=1$ ). This raster set will be used to compute urban fragmentation indexes.

Geoprocessing was performed using ArcGIS 10.0 (ESRI); vectors and imagery were previously projected onto UTM $21 \mathrm{~S}$ datum WGS84 coordinate system (EPSG: 32721 ).

\subsection{Urban fragmentation and its measurement}

\subsubsection{The core open space ratio}

The Open Space is a pixel that is surrounded by more than $50 \%$ of its neighbours built in a circle area of $1 \mathrm{~km}^{2}$. (Angel, 2010). In this case, we use images with pixels of $30 \mathrm{~m}$ side, then there are 980 neighbourhood pixels.

At the same time, the built-up areas of cities are classified into three types: (1) urban cores, (2) suburban areas, and (3) rural areas. Urban core pixels were defined as built-up pixels surrounded by 50 percent of more built-up pixels in a $1 \mathrm{~km}^{2}$ circle around them. Suburban pixels were defined as built-up pixels surrounded by 10 to 50 percent built-up pixels in a $1 \mathrm{~km}^{2}$ circle around them. Rural pixels were defined as built-up pixels surrounded by less than 10 percent built-up pixels in a $1 \mathrm{~km}^{2}$ circle around them. These classifications are distinctions between urban, suburban, and rural areas based solely on their level of fragmentation and not on the respective densities in their built-up areas.

The Core Open Space Ratio is estimated using the Open Space pixels detected by each core type: Urban, Suburban and Rural. The metric applied on urban core constitutes a useful metric for measuring fragmentation. It focuses attention on the urban core as a whole while leaving aside for the time being the fragmentation of open space in suburban areas.

\subsubsection{Fractal dimension and entropical regimes}

Mathematically, fractal dimension (D) is a number ranging between 0 and 2 that points out how hierarchically organized is a given pattern of built up area (Encarnação et al., 2012). The total area is divided into cells of $1 \mathrm{~km}$ side. A particular D is assigned to each cell, which is computed by using the box counting algorithm (Mandelbrot, Macmillan,1983).

Entropy is the physical notion related to the uncertainty degree about a given system. A D-dependent entropy function $S(D)$ is defined by (Encarnação et al., 2012) and provides a natural classification for the built-up area patterns of the cells. According to (Gaudiano, 2015), minimum uncertainty/uncontrollability of patterns corresponds to $\mathrm{D}=0$ and $\mathrm{D}=2$, which represents the almost rural (empty) and compactified urban patterns, respectively. Extreme values are predictable, in the case of the rural cells because they do not show substantial changes of the built areas in a long time. On the other hand, highly urbanized compact cells are also highly predictable because there is almost no room for new built-up areas, and consequently there is going on an essentially nondynamical situation inside of those cells. 
In contrast, intermediate values of $\mathrm{D}$ correspond to the most diverse possible fractal patterns of built areas (past, present or future): this means that the knowledge about $\mathrm{D}$ (and the built-up area) is scarce, and consequently, to lead, controlling or predicting the behaviour of the built-up areas inside of the cell becomes a harder task (Gaudiano, 2015). In addition, since $\mathrm{S}(\mathrm{D})$ is non-monotonous (Fig. 2) the rate of change with respect to D also plays and important role (Gaudiano, 2015). Thus, for $\mathrm{D}<1.78$ entropy increases. For $\mathrm{D}>1.78$, entropy reduces dramatically, being the patterns every time more predictable as they compactify. In terms of controllability, some further regimes can be identified (Gaudiano, 2015). On range $1.26<\mathrm{D}<1.54$ uncertainty is increasing, and is still relatively low. For $1.54<\mathrm{D}<1.78$ uncontrollability is high and increasing. Thus $\mathrm{D}=1.54$ points out an entropical limit, in which the chances of controlling the cell built up area system are not low. When $\mathrm{D}>1.78$, applying any governmental policy could be useless or, in principle, against the natural system tendency.

The algorithm to compute $\mathrm{D}$ was developed in Octave (Eaton, Bateman, Hauberg, \& Wehbring, 2017).

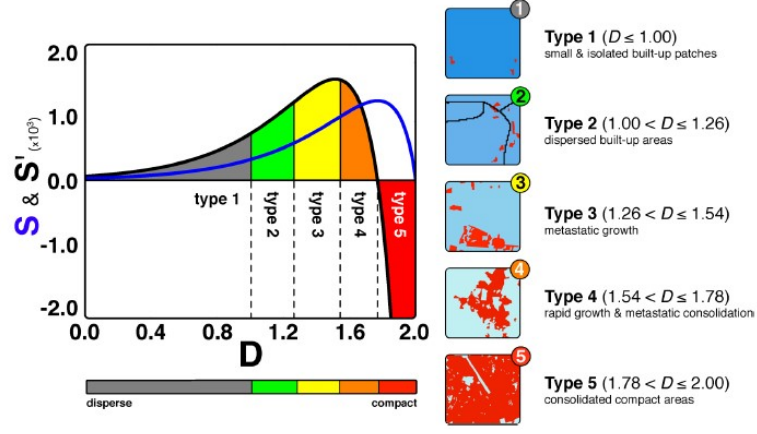

Figure 2. Types of built-up areas. Source: (Encarnação et al., 2012)

\section{RESULTS}

\subsection{Extraction of impervious surfaces}

The overall accuracy of extraction of impervious surfaces is between $79.9 \%$ and $98.03 \%$. Table 1 shows the quantification of impervious surfaces in the projected urban area and the percentage of relative increase per period.

Results indicate that the five studied urban areas underwent a continuous impervious surface expansion during the period under consideration. The highest increment is detected between 2001 and 2019 for Gral Rodriguez (173\%), and then between 1986 and 2001 for Moreno (145\%). Figure 3 (top), shows a contrast between pervious and impervious surfaces obtained in 1986 and 2019.

The municipalities located in the northeast present new impervious areas, in line with the means of transport (highways and railways) that connect them with the federal capital. The new centres have commercial and industrial characteristics that contrast with the idea of dormitory cities becoming a centre in its own right.

\begin{tabular}{|c|c|c|c|c|}
\hline \multirow{2}{*}{ Municipality } & \multicolumn{3}{|c|}{ Impervious surface (\%) } & Total surface \\
\cline { 2 - 4 } & 1986 & 2001 & 2019 & \\
\hline Mercedes & 0.46 & 0.58 & 0.89 & 1050.8 \\
\hline Luján & 1.04 & 1.28 & 2.20 & 755.7 \\
\hline Gral. Rodríguez & 0.87 & 1.18 & 3.22 & 383.5 \\
\hline Moreno & 4.71 & 11.57 & 22.77 & 185.9 \\
\hline Pilar & 2.38 & 4.63 & 10.26 & 367.2 \\
\hline
\end{tabular}

Table 1. Impervious surface in urban areas per year

\subsection{Fragmentation indicators}

The first fragmentation index computed was Core Open Space Ratio by the built-up area types. Following Angel (2010), we categorized the study area in Urban Core, Suburban Core and Rural by year (Fig 3 bottom). The results show the continuous formation of new urban centres in the municipalities closest to the federal capital: Moreno and Pilar. The first shows two urban centres in 1986 and twelve in 2019. The second shows one centre in 1986 and seven in 2019. Both General Rodriguez and Lujan presented two urban centres in 2019. Only Mercedes presented one urban centre in the evaluated period.

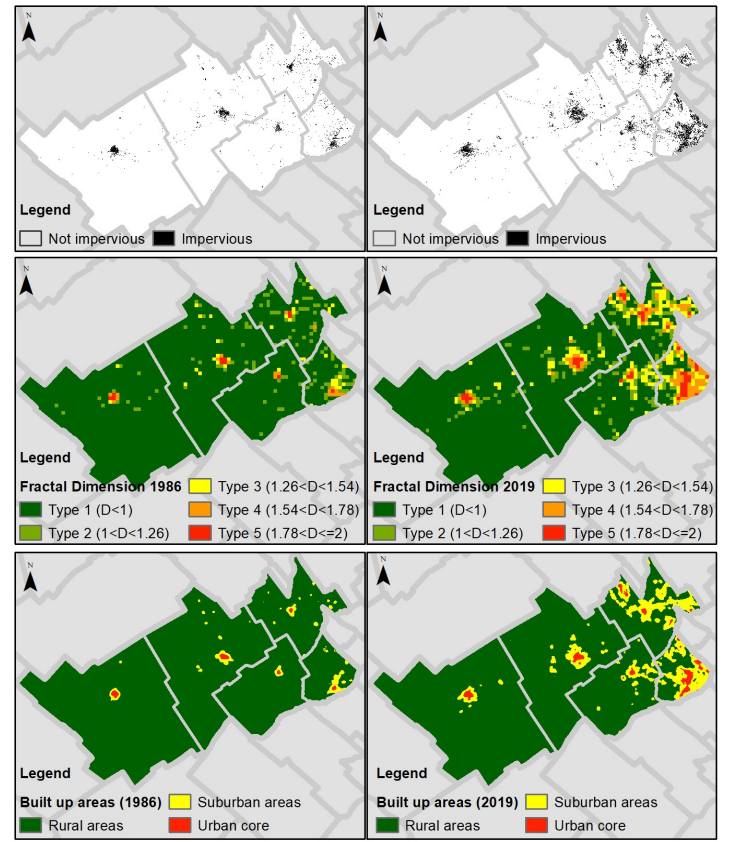

Figure 3. Spatio temporal types of built-up areas in municipalities

Then, the proportion represented by the categories of built-up areas in each party was calculated (Fig 4). 


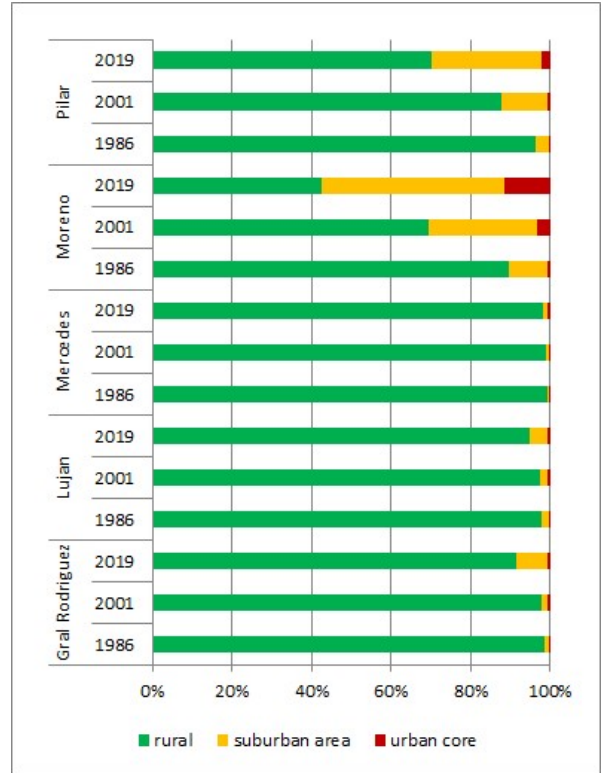

Figure 4. Built-up areas ratio by municipality

In this case Moreno present the highest variability respects urban and suburban cores (1986: 1817.4ha; 2001: 5077.3ha; 2019: 8538.2ha), followed by Pilar (1986: 1247.2ha; 2001: 4188.4ha; 2019: 10175.3ha). The others municipalities does not present significant changes in their total built up areas by year. Table 2 shows the Core Open Space Ratio by the urban and suburban cores.

\begin{tabular}{|c|c|c|c|}
\hline \multirow{3}{*}{ Municipality } & Years & \multicolumn{2}{|c|}{ Core Open Space Ratio } \\
\cline { 2 - 4 } & 1986 & Urban core & Suburban core \\
\hline \multirow{3}{*}{ Gujal Rodriguez } & 2001 & 0.23 & 0.73 \\
\cline { 2 - 4 } & 2019 & 0.30 & 0.72 \\
\hline \multirow{3}{*}{ Mercedes } & 1986 & 0.25 & 0.76 \\
\cline { 2 - 4 } & 2001 & 0.25 & 0.75 \\
\cline { 2 - 4 } & 2019 & 0,29 & 0.73 \\
\hline \multirow{3}{*}{ Moreno } & 1986 & 0,14 & 0,73 \\
\cline { 2 - 4 } & 2001 & 0,18 & 0,74 \\
\cline { 2 - 4 } & 2019 & 0,22 & 0,73 \\
\cline { 2 - 4 } & 1986 & 0,24 & 0,72 \\
\cline { 2 - 4 } & 2001 & 0,31 & 0,76 \\
\hline \multirow{3}{*}{ Pilar } & 2019 & 0,31 & 0,71 \\
\cline { 2 - 4 } & 1986 & 0,20 & 0,70 \\
\cline { 2 - 4 } & 2001 & 0,26 & 0,77 \\
\cline { 2 - 4 } & 2019 & 0,35 & 0,73 \\
\hline
\end{tabular}

Table 2. Core Open Space Ratio in built-up areas

The values indicate that the 1986 urban cores presented a core open space ratio smaller than the present ones. It means that the increase of impervious surface implies the variability of urban voids. In the cases of Pilar and Moreno, which are the municipalities that have formed more urban cores, also present the largest open spaces ratio ( 0.35 and 0.31 , respectively). Their suburban cores, present an open space ratio higher than 70 percent along the time.
The second metric compute was the fractal dimension (D). The Fig 3 (middle) shows the spatio-temporal evolution in terms of D. The global results indicate that this group of municipalities present an increment of D values: 0.24 (DS: 0.40) in 1986, 0.27 (DS: 0.45 ) in 2001 and 0.42 (DS: 0.56 ) in 2019. Those global results are less than values found by Buzai (2011) for the Great Buenos Aires in $1991(\mathrm{D}=1.39)$ and confirms the need for more accurate metrics.

Maps present large areas with $\mathrm{D}$ values less than 1, which still denotes the presence of small dispersed constructions. On the other hand, the presence and growth of the proportion of areas with urban regime type 4 (rapid growth and consolidation) is constant. It should be noted that in 1986 the compact areas detected (Type 5) overlapped with the old urban centres that currently fulfil administrative functions. The 2019 map presents new compact areas in both Moreno and Pilar. In the first, their activities are associated with residential and commercial use, while in the second, industrial use is added.

In order to evaluate the behaviour of built area vs D we extrapolated the data to a pixel side of $15 \mathrm{~m}$ by multiplying each area $\mathrm{A}$ by $2^{\mathrm{D}}$ (Gaudiano, 2015). Fig. (5) shows that the built area does not follow an one-to-one correspondence with respect to $\mathrm{D}$, but it is bounded by two function L(D) (Eq. 2) and U(D) (Eq. 3). Both mathematical properties are consistent with Encarnação (2012) and Gaudiano (2015).

$\mathrm{L}(\mathrm{D})=2^{\mathrm{mD}}$

$\mathrm{U}(\mathrm{D})=\lambda^{2} 2^{\mathrm{m}(\mathrm{D}-2)}$

where $\quad \mathrm{m}=5 ; \lambda=66.6$

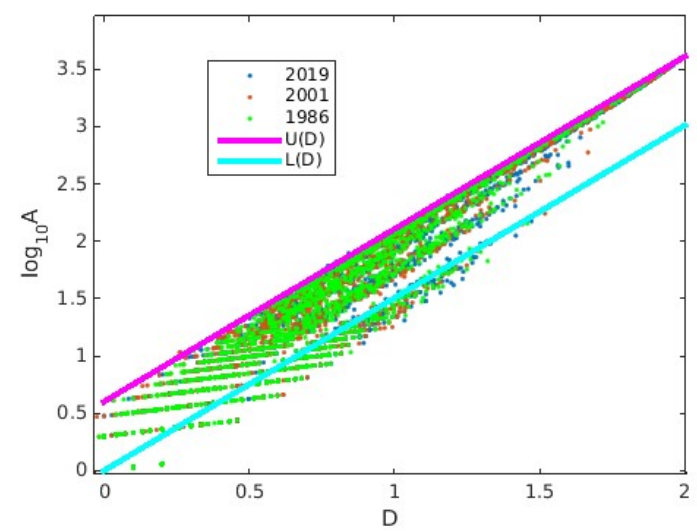

Figure 5. Log-scale of built-up area in each cell vs. fractal dimension (D). Note there is not an one-to-one correspondence: the built up area range is bounded by L(D) and U(D).

Also, the situation of each municipality is analysed, and there is evidence of unequal transformation. According to the results obtained for the years 1986, 2001 and 2019 the values of global $\mathrm{D}$ for each municipality are:

Moreno: 0,74 (DS: 0,48); 0,99 (DS: 0,55); 1,32 (DS: 0,50)

Pilar: 0,55 (DS: 0,43); 0,65 (DS: 0,52); 0,95 (DS: 0,54)

Gral. Rodriguez: 0,23 (DS: 0,38); 0,24 (DS: 0,37); 0,49 (DS: 0,52 )

Mercedes: 0,08 (DS: 0,25); 0,08 (DS: 0,25); 0,13 (DS: 0,33)

Lujan: 0,20 (DS: 0,37); 0,20 (DS: 0,38); 0,31 (DS: 0,47)

To visualize the great variability along the time and by municipality we plot rate of urban regime types (Fig 6) 


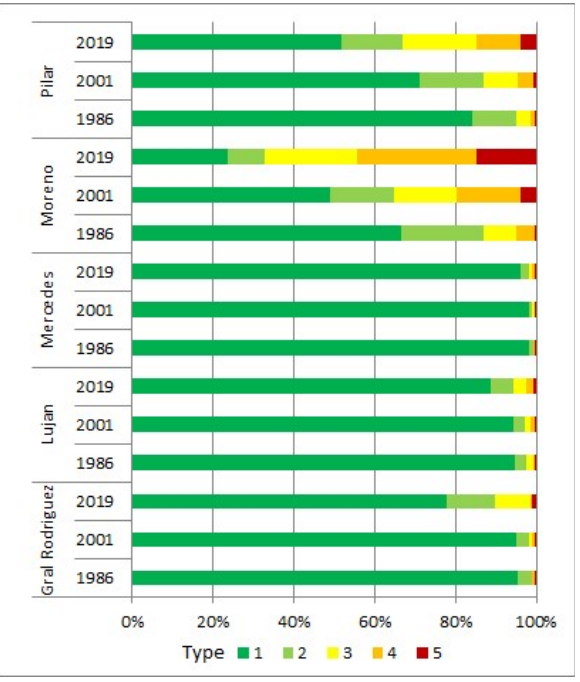

Figure 6. Built-up areas based on urban regimes

The municipalities with the greatest variability and diversity of urban regimes are Moreno and Pilar. The proportion of the compact or consolidated regime (Type 5) in Moreno has increased from $0.5 \%$ to $14.6 \%$ and its zones with dispersed constructions (Type 1 and 2) have decreased from $86.8 \%$ to $32.8 \%$. In addition fast-growing areas with metastatic consolidation (Type 4) have increased from $4.6 \%$ to $29.8 \%$. In the case of Pilar, dispersed constructions have predominated at all times (from $95.0 \%$ to $66.7 \%$ ). Although its compact zones represent less than $4.0 \%$ yet, a growth of the type 4 urban regime zones (from $0.7 \%$ to $10.7 \%$ ) is detected. According Encarnação (2012) types 3 and 4 are the regions where planning must act more effectively. Indeed, such proximate planning will ensure well-designed transitions into more compact configurations.

Lastly, the response of fractal dimension is calculated by zoning class (Ley 8912/77, 1977): Agricultural (Ag), Commercial (Co), Industrial (In), Medium density residential (MDR), Low density residential (LDR), Future development areas (FDA). Table 3 shows fractal dimension mean by class zoning.

\begin{tabular}{|c|c|c|c|c|c|c|c|c|c|c|c|}
\hline \multirow{2}{*}{ Zoning } & $\begin{array}{c}\text { Gral } \\
\text { Rodriguez }\end{array}$ & \multicolumn{2}{c|}{ Lujan } & \multicolumn{2}{c|}{ Mercedes } & \multicolumn{2}{c|}{ Moreno } & \multicolumn{2}{|c|}{ Pilar } \\
\cline { 2 - 13 } & 1986 & 2019 & 1986 & 2019 & 1986 & 2019 & 1986 & 2019 & 1986 & 2019 \\
\hline $\mathrm{Ag}$ & 0.18 & 0.37 & 0.10 & 0.16 & 0.06 & 0.09 & 0.36 & 0.96 & 0.42 & 0.71 \\
\hline Co & - & - & 1.85 & 1.86 & 0.88 & 1.11 & 0.75 & 1.41 & 0.77 & 1.17 \\
\hline FDA & 0.47 & 0.89 & - & - & 0.30 & 0.76 & 0.70 & 1.64 & 0.95 & 1.46 \\
\hline In & 0.34 & 0.94 & 0.45 & 1.08 & 0.06 & 0.35 & 0.59 & 1.24 & 0.69 & 1.11 \\
\hline LDR & 0.28 & 0.66 & 0.24 & 0.36 & - & - & 0.40 & 0.96 & 0.49 & 0.96 \\
\hline MDR & 0.80 & 1.21 & 0.75 & 1.15 & 0.73 & 1.17 & 0.93 & 1.53 & 0.73 & 1.19 \\
\hline
\end{tabular}

Table 3. Fractal dimension by zoning.

The analysis of fractal dimensional means also shows the diversity of spatial configuration by types of land use. For example, in the agriculture category $(\mathrm{Ag})$ there are values of $\mathrm{D}$ closer to 1 in Moreno and Pilar, due to the intensive development of the activity in greenhouses.
The commercial category (Co) in 2019 reaches values of D that indicate a metastatic growth still controllable (Type 3), only in the case of Lujan this zone is presented as compact (Type 5) since 1986 .

The FDA category presents significant changes in Moreno from a dispersed urban regime (Type 1) to another in metastatic growth (Type 4).

The industrial activity (In) presents a maximum D associated with dispersed constructions (Type 2) as a result of municipal and provincial promotion and regulation.

Finally, the results on residential areas are consistent with provincial planning. On the one hand LDR presents values of D less than 1 which describes a regime of dispersed constructions (Type 1). On the other hand, MDR presents values higher than LDR and only in the case of Moreno presents an urban regime of controllable metastatic growth (Type 3 ).

\section{DISCUSSION}

The Core Open Space Ratio and Fractal Dimension coincide spatially in the detection of urban cores and compact zones. Although they differ in the proportion of urban centres, D presents different degrees in the last range of compaction. According to the Core Open Space Ratio, these areas can be considered suburban and, consequently, their open spaces must be considered as a strip in transition to consolidation.

Both metrics could be applied in different periods of analysis however the fractal dimension gives a precise description of the sequence of the occupation of space. If rapid category changes are detected, it is possible to predict their evolution and to limit the space where the phenomenon of growth or consolidation develops.

This work completes and complements the results of Angel (2010) and Buzai (2011), where global data are presented for different agglomerations, also provide measures of growth or consolidation in their peri-urban areas.

Future work is expected to replicate classification techniques throughout the metropolitan areas of Buenos Aires and estimate fragmentation metrics that support fair and equitable spatial planning in the medium and long term.

\section{REFERENCES}

Angel, S., Parent, J., \& Civco, D. L. (2010). The Fragmentation of Urban Footprints: Global Evidence of Sprawl, 1990-2000. Retrieved from: Lincoln Institute of Land Policy website: https://www.lincolninst.edu/publications/workingpapers/fragmentation-urban-footprints

Angiuli, E., \& Trianni, G. (2014). Urban Mapping in Landsat Images Based on Normalized Difference Spectral Vector. IEEE Geoscience and Remote Sensing Letters, 11(3), 661-665. https://doi.org/10.1109/LGRS.2013.2274327

Burges, C. J. C. (1998). A Tutorial on Support Vector Machines for Pattern Recognition. Data Mining and Knowledge Discovery, 2, 121-167. 
Buzai, G. D., \& Baxendale, C. A. (2011). Análisis Socioespacial con Sistemas de Información Geográfica. Perspectiva científica. Temáticas de Base raster- Tomo I. Lugar Editorial S.A.

Decreto Ley 8912/77 de Ordenamiento Territorial y Uso del suelo. PCIA. DE BUENOS AIRES

Eaton, J. W., Bateman, D., Hauberg, S., \& Wehbring, R. (2017). GNU Octave version 4.2.1 manual: A high-level interactive language for numerical computations. Retrieved from: https://www.gnu.org/software/octave/doc/v4.2.1/

Encarnação, S., Gaudiano, M., Santos, F. C., Tenedório, J. A., \& Pacheco, J. M. (2012). Fractal cartography of urban areas. Scientific Reports, 2(1). https://doi.org/10.1038/srep00527

ENVI (Versión 4.8). (s/f). Boulder, Colorado: Exelis Visual Information Solutions.

ESRI 2011. ArcGIS Desktop: Release 10. Redlands, CA: Environmental Systems Research Institute.

Favelukes, G., Novick, A., \& Zanzottera, G. (2016). Cartografías del Área Metropolitana de Buenos Aires según Patricio Randle, César Vapñarsky y Horacio Torres. Estudios Del Hábitat, 14(2).

Flores, A. P. (2017). Estudio de la dinámica de los asentamientos periurbanos bonaerenses. El caso de estudio de los partidos de Moreno, Pilar y Tigre. (Master's Thesis). Universidad Nacional de Córdoba, Córdoba, Argentina.

Gaudiano, M. E. (2015). An entropical characterization for complex systems becoming out of control. Physica A: Statistical Mechanics and Its Applications, 440, 185-199. https://doi.org/10.1016/j.physa.2015.08.023

Gorelick, N., Hancher, M., Dixon, M., Ilyushchenko, S., Thau, D., \& Moore, R. (2017). Google Earth Engine: Planetary-scale geospatial analysis for everyone. Remote Sensing of Environment. https://doi.org/10.1016/j.rse.2017.06.031

Instituto Nacional de Estadísticas y Censos. (s/f). Censo de Hogares y Viviendas, Instituto Nacional de Estadísticas y Censos 2010. Retrieved from: http://200.51.91.245/argbin/RpWebEngine.exe/PortalAction?\& MODE $=$ MAIN\&BASE $=$ CPV2010B\&MAIN $=$ WebServerMain.i $\mathrm{nl}$

Longley, P A, H., R. J. (1999). Towards a new digital data infraestrucutre for urban analysis and modelling. Environment and Planning B: Planning and Design, 26, 855-878.

Mandelbrot, B., 1983. The Fractal Geometry of Nature, Macmillan.

Masek, J. G., Lindsay, F. E., \& Goward, S. N. (2000). Dynamics of urban growth in the Washington DC metropolitan area, 1973-1996, from Landsat observations. International Journal of Remote Sensing, 21(18), 3473-3486. https://doi.org/10.1080/014311600750037507

Patel, N. N., Angiuli, E., Gamba, P., Gaughan, A., Lisini, G., Stevens, F. R., ... Trianni, G. (2015). Multitemporal settlement and population mapping from Landsat using Google Earth
Engine. International Journal of Applied Earth Observation and Geoinformation, 35, 199-208. https://doi.org/10.1016/j.jag.2014.09.005

Schneider, A., \& Woodcock, C. E. (2008). Compact, Dispersed, Fragmented, Extensive? A Comparison of Urban Growth in Twenty-five Global Cities using Remotely Sensed Data, Pattern Metrics and Census Information. Urban Studies, 45(3), 659692. https://doi.org/10.1177/0042098007087340

Shen, G. (2002). Fractal dimension and fractal growth of urbanized areas. International Journal of Geographical Information $\quad$ Science, $\quad 16(5), \quad 419-437$. https://doi.org/10.1080/13658810210137013

Swenson, J. J., \& Franklin, J. (2000). The effects of future urban development on habitat fragmentation in the Santa Monica Mountains. Landscape Ecology, 15(8), 713-730.

Taubenböck, H., Esch, T., Felbier, A., Wiesner, M., Roth, A., \& Dech, S. (2012). Monitoring urbanization in mega cities from space. Remote Sensing of Environment, 117, 162-176. https://doi.org/10.1016/j.rse.2011.09.015

Zhang, H., \& Xu, R. (2018). Exploring the optimal integration levels between SAR and optical data for better urban land cover mapping in the Pearl River Delta. International Journal of Applied Earth Observation and Geoinformation, 64, 87-95. https://doi.org/10.1016/j.jag.2017.08.013

\section{APPENDIX}

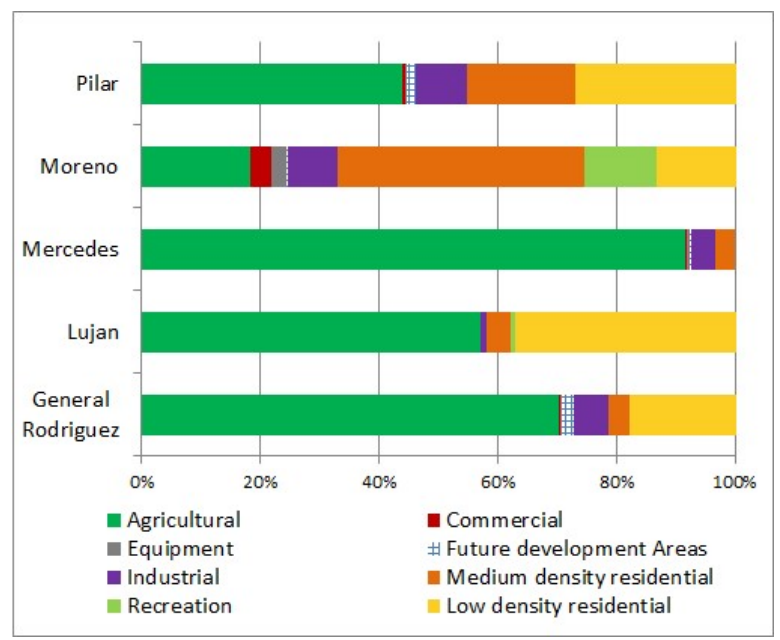

Figure 7. The urban zoning in the study area (Ley 8912/77, 1977) 